\title{
The importance of embedding meta skills in computer science graduate apprenticeship programmes.
}

\author{
YOUNG, T.
} personal use. Not for redistribution. The definitive Version of Record was published in Proceedings of the 25th Association for Computing Machinery (ACM) Innovation and technology in computer science education conference 2020 (ITiCSE '20), 15-19 June 2020, Trondheim, Norway, https://doi.org/10.1145/3341525.3394010. 


\title{
The Importance of Embedding Meta Skills in Computer Science Graduate Apprenticeship Programmes
}

\author{
Tiffany Young \\ Robert Gordon University \\ Aberdeen, Scotland \\ t.young3@rgu.ac.uk
}

\begin{abstract}
The purpose of this proposal is to investigate the need for the increased focus on developing transferable and meta skills of Graduate Apprentice Computer Science students and how the advancements of technology can impact the need for this. The Fourth Industrial Revolution is evolving at an exponential rate and is shaping industry and the workplace. The need for developing higher-order skills more explicitly, rather than through the hidden curriculum, will be investigated to ensure students are prepared for the constantly changing landscape of the workplace.
\end{abstract}

\section{CCS CONCEPTS}

- Social and professional topics $\rightarrow$ Computing education; Employment issues.

\section{KEYWORDS}

Graduate Apprenticeship, Work-Based Learning, Employability,

Meta Skills, Transferable Skills, Hidden Curriculum

\section{CONTEXT AND MOTIVATION}

Graduate Apprenticeships were introduced in Scotland in 2017 and

look to combine academic knowledge and qualification recogni-tion along with practical skills development. Graduate Apprentices

work full time within their related field, whilst undertaking full time higher education study. The importance of students relating

their academic theory and applying this within the context of their workplace, is much more prevalent than traditional oncampus

students as they have continuous exposure to industry and the application and importance of the academic theory. There is of-

ten a misconception that, as Graduate Apprenticeship students are already integrated in a work-based environment, personal and pro-fessional skills are developed as a matter of course but research suggests transferring soft skills to the workplace is challenging [10].

Permission to make digital or hard copies of part or all of this work for personal or classroom use is granted without fee provided that copies are not made or distributed for profit or commercial advantage and that copies bear this notice and the full citation on the first page. Copyrights for third-party components of this work

must be honored. For all other uses, contact the owner/author(s).

ITiCSE '20, June 15-19, 2020, Trondheim, Norway

() 2020 Copyright held by the owner/author(s).
For most, these are currently underdeveloped therefore explicit development of these skills is essential as they don't occur purely by osmosis. With continuous growth and rapid advancements in technology, it is important for institutions to ensure they are equipping students with the relevant skills to ensure they prepared for the ever-evolving workplace.

\section{LITERATURE REVIEW}

Advancements in technology has caused significant disruption which have, and will continue to have, an unpredictable impacted on society, the economy, our environment and governmental policies. With the rapid changes in technology, the workplace is constantly evolving and as a result it is pertinent that Scotland, as a society, focus and thrive to develop the workforce to be well equip for both current and future changes. As highlighted by SDS, the development of meta-skills are essential for the success of individuals in addition to society as a whole [8]. These meta-skills assist in the development of adaptive learners with the focus on "skills to excel; to collaborate and empathise with others and to create our own futures" [8](SDS, 2018, page 8). Embedding these meta-skills within the higher education curriculum will contribute to the development of more adaptive learners which in-turn will support individuals to achieve and maintain employment throughout their careers. These meta-skills are not a new concept in themselves but there is an increasing importance on the understanding, focus and value of these skills [8].

These meta-skills have been classified into the following categories: self-management, social intelligence and innovation [8]. None of the skills exist in pure isolation as there are interdependent. With the advancements in technology, we now have an abundance of information at our fingertips, which has resulted in information overload. Having the ability to filter out the useful and meaningful content and remain focussed has a positive impact on the overall productivity. Having the ability to understand how you can most effectively learn and successfully identify your own strengths and weaknesses, can allow you to focus and adapt to the environment that you are in.

Social intelligence, specifically emotional intelligence is a contributing factor towards one's attitude and in turn, career success [1], with $87 \%$ of graduate recruiters identify graduate attitudes amongst the three most important factors [7]. As identified by McKinsey, social and emotional capabilities are amongst those with the lowest automation potential [8]. Arming students with these skills is an effective way to combat the fast-developing landscape of jobs. 


\section{PROBLEM STATEMENT}

The continual shift towards technology and automation increases the uncertainty of the changing workplace. According to Deloitte's research, it is estimated that up to $35 \%$ of UK and $77 \%$ of Chinese jobs are at risk of automation within the next 10 to 20 years [2]. If this is the case, there will be more need than ever to have people to 1) possess the skills to fill the new employment opportunities generated by this shift; 2) develop the higher order, meta skills for jobs that are not automated. As highlighted by McKinsey, the areas with a lower potential to become automated are primarily those with social and emotional components [8].

As identified by the Higher Education Statistics Agency, Computing Science students have the highest unemployment rate of all full-time, UK degree leavers, sitting at 9.5\% [5]. Although there is no single reason for the graduate employability situation [9], it is believed that the increase in popularity of computing science degrees has resulted in a lack of viable employment options available for graduates due to saturation of the job market [6]. On the other hand, it was found that as much as $29 \%$ of businesses have increased their graduate intake with an overall increase of $+20 \%$ of graduate recruitment [7]. This in itself is not the only factor contributing to high unemployment rates. "Concerns from industry about the skills, agility and work-readiness" $[3,6]$ are contributing to the high graduate unemployment rates. It is highlighted that Computer Science graduates as a whole appear to be misaligned with the needs of employers. Employers report a number of common issues with regards to graduate's skill sets, lacking work experience and soft skills are among the most often quoted [9].

\section{RESEARCH GOALS}

Should a more holistic and structured approach be taken by universities by focusing on the development of transferable and soft skills using a distinct module in the curriculum. As detailed in the QAA's Characteristic Statement "Apprenticeships should develop transferable and lifelong learning skills that will enable the graduate apprentice to maintain employment throughout their working life" [4]. Due to the unpredictability of the changing work environment, the development of transferable and soft skills is of great importance to ensure a sustainable economy can be built. With routine tasks and jobs becoming more automated by the advancements in artificial intelligence (AI), the diversification of workers is required to adapt to the changing work environment. This places more emphasis on jobs that require creativity, that only humans can do [8]. As a result of this, it is becoming more pertinent for Higher Education Institutes to focus on developing students' soft skills, including but not limited to communication, teamwork, leadership, problem solving, adaptability and interpersonal skills [10]. Through this research an investigation will be made into the impact of the integration of these skills into the curriculum to establish if these further enhance student's skill sets and respond to the changing workplace.

\section{RESEARCH METHODS}

Robert Gordon University is trialling a Professional Development module integrated within the first year of the Graduate Apprenticeship (GA) programmes within the School of Computer Science and Digital Media. Students will carry out a self-assessment at the start of the module to allow them to identify how employable they view themselves. A reassessment using the same self-assessment questionnaire, will then be complete at the end of the module to identify any improvements students have made. This will be one metric to measure the impact and success of module at developing the student soft skills required for employment. In addition to this, data will be captured in the university student surveys and through a focus group after the module has concluded.

\section{CONTRIBUTIONS}

The importance of developing solid transferable, soft skills is more pertinent than ever, to ensure a successful, prosperous career. This is particularly true for computing science students as a combination of both hard and soft skills are what industry is needing from its graduates. Embedding soft skill development in the higher education curriculum with prove beneficial to the individual students and the wider society. Adaptive learners are essential to the success of the ever-changing workplace as automation impacts the job market and shapes the future of work. An increase in focus and value must be put on developing the meta skills that are essential for graduates to thrive in the changing landscape of industry. This is an opportunity for people with the right skill set and specialist knowledge to fill these areas. With the development of their meta skills such as self-awareness, communication, problem solving, leadership and professionalism, to arm students with all the soft skills desired and required by employers. This in turn will contribute to their success through their careers with their ability to adapt to change and embrace uncertainty.

\section{REFERENCES}

[1] M. Coetzee and D. Schreuder. 2011. The between career anchors, emotional intelligence and employability satisfaction among workers in the service industry. Southern African Business Review 15, 3 (2011). https://www.ajol.info/index.php/ sabr/article/viewFile/76406/66864 Accessed: 7/3/2020.

[2] Deloitte. 2016. Talent for survival: Essential Skills for Humans Working in the Machine Age. https://www2.deloitte.com/content/dam/Deloitte/uk/Documents/ Growth/deloitte-uk-talent-for-survival-report.pdf Accessed: 7/3/2020.

[3] Times Higher Education. 2016. What should we be teaching the next generation of computer scientists? https:/www.timeshighereducation.com/features/whatshould-we-be-teaching-the-next-generation-of-computer-scientists 7/3/2020.

[4] The Quality Assurance Agency for Higher Education (QAA). 2014. The Framework of HE Qualifications of UK Degree-Awarding Bodies. https://www.qaa.ac. uk/quality-code/qualifications-and-credit-frameworks Accessed: 7/3/2020.

[5] Higher Education Statistics Agency Limited (HESA). 2018. Destinations of Leavers 2016/17. (2018). https://www.hesa.ac.uk/data-and-analysis/publications/ destinations-2016-17/introduction Accessed: 7/3/2020.

[6] Study International. 2016. UK Computer Science has the highest rate of unemployed graduates. https:/www.studyinternational.com/news/uk-computerscience-has-the-highest-rate-of-unemployed-graduates/ Accessed: 7/3/2020.

[7] The Confederation of British Industry (CBI). 2016. The Right Combination: CBI/Pearson Education and Skills Survey 2016. http://www. makingthemostofmasters.ac.uk/media/microsites/mmm/documents/cbieducation-and-skills-survey-2016.pdf

[8] Skills Development Scotland (SDS). 2018. Skills 4.0 A Skills Model to Drive Scotland's Future. https://www.skillsdevelopmentscotland.co.uk/media/44684/ skills-40_a-skills-model.pdf Accessed: 7/3/2020.

[9] N. Shadbolt. 2016. Review of Computer Sciences Degree Accreditation and Graduate Employability. https://dera.ioe.ac.uk/16232/2/ind-16-5-shadbolt-reviewcomputer-science-graduate-employability_Redacted.pdf

[10] A. Williams. 2015. Soft Skills Perceived by Students and Employers as Relevant Employability Skills. https://scholarworks.waldenu.edu/cgi/viewcontent.cgi? referer=https://scholar.google.co.uk/\&httpsredir $=1 \& \operatorname{article}=2426 \&$ context $=$ dissertations[Accessed: 7/3/2020. 